\title{
Patent Ductus Arteriosus Size Estimation by Echocardiography and Angiography: A Comparative study
}

\author{
Karim T*, Hussain MZ, Islam MT, Alam S, Baruea C, Bhuiyan MMR, Bhadra S \\ Department of Paediatric Cardiology, Bangabandhu Sheikh Mujib Medical University, Dhaka, \\ Bangladesh
}

\begin{abstract}
Background: Patent ductus arteriosus (PDA) is the common congenital heart disease that needs medical attention to deal with disease related complications. With the advancement of transcatheter intervention closure of PDA by coil or Amplatzer devices, has become acceptable alternate to surgical ligation.

Objects: The study was aimed estimation of size of patent ductus arteriosus by 2D and colour Doppler echocardiography and to compared with the data obtained by angiography.

Methods: This retrospective study was conducted during January 2014 to December 2016 and data were collected from records of Paediatric Cardiology Department of BSMMU. Fifty children were included in the study. All the cases were assessed with 2D echocardiography, color doppler echocardiography (CDE) and angiography and underwent device closure. Estimation of PDA size were done with 2D, color doppler and angoigraphically and were compared and analysed statistically.

Results: Out of 50 cases, ages ranged from 10 months to 28 years with a mean age of $5.75 \pm 5.33$ years. The mean weight was $16.3 \pm 10.58 \mathrm{Kg}$ with a range of $5.5 \mathrm{Kg}$ to $54 \mathrm{~kg}$ and sex distribution was 16 males and 34 females. Visualization of the patent ductus arteriosus was achieved from short-axis and suprasternal-axis views in all children with CDE. The mean diameter of pulmonary end of patent ductus arteriosus was $3.45 \pm 0.96$ millimetre with a range from 1.45 to 6.20 millimetres in CDE. The mean diameter of aortic end of PDA $4.64 \pm 1.30$ with a range of 2.50 to 9.50 in $2 \mathrm{D}$ and $\mathrm{CDE}$ respectively. The mean angiographic measurement of aortic end of PDA was 5.35 \pm 1.42 with a range of 2.60 to 10 . Both 2D echo and CDE correlated significantly ( $p$ value <.0.001) with angiographic measurement at both pulmonary and aortic ends. The Pearson correlation coefficient for 2D echo and $\mathrm{CDE}$ are 0.967 and 0.973 respectively at pulmonary end indicating that CDE correlates marginally better than 2D echo with angiographic measurements at the pulmonary end. Similarly at the aortic end (ampulla), the Pearson correlation coefficient for 2D echo and CDE are 0.955 and 0.966 respectively indicating that both correlates with angiography but CDE is better correlates.

Conclusion: It may concluded that it is almost always possible to measure the dimensions of the patent ductus arteriosus with colour doppler echocardiography, keeping in mind that color doppler echocardiographic measurement overestimates the angiographic measurement of the pulmonary side of the patent ductus arteriosus and underestimates its aortic side.
\end{abstract}

Keywords: PDA Size, Echocardiography, Angiography, Colour doppler echocardiograpy

\section{Introduction}

One of the most common congenital cardiac condition in pediatric patients is patent ductus arteriosus, and recently assumed major importance as a life threating disease of small premature infants, who now survive due to advances in neonatology ${ }^{1-4}$ Alternative to the surgical ligation,

\footnotetext{
*Correspondence: Tahmina Karim, Department of Paediatric Cardiology, Bangabandhu Sheikh Mujib Medical University, Dhaka, Bangladesh; e-mail: dr.tkarim@yahoo.com
}

recently closure of patent ductus arteriosus with coil or amplatzer devices is well accepted..$^{5-10}$

The precise measurement of patent ductus arteriosus by a non-invasive method like echocardiography has now become clinically more important than in the past, when surgical ligation was the only corrective procedure available for ductal closure. ${ }^{11,12}$

The device selection is typically based on ductal morphology and dimensions. Inaccurate 
measurements and, therefore, device selection may result in adverse events, including systemic or pulmonary embolisation, incomplete ductal closure and haemolysis. Thus, when transcatheter occlusion is considered in the treatment of PDA acquiring accurate ductal dimensions is necessary for appropriate device selection and sizing to ensure complete occlusion and to prevent inappropriate embolisation. The noninvasive estimation of the dimensions of patent ductus arteriosus is desirable to avoid unsuccessful catheter intervention. The combined twodimensional echocardiography and colour Doppler echocardiography in children can a the presence of a patent ductus arteriosus with a- sensitivity $96 \%$ and specificity $100 \%$ and is highly reliable - and also asses its morphology. ${ }^{11,13,14}$ Estimation of patent ductus arteriosus size by two-dimensional echocardiography is usually difficult because of its small size and difficulty in the detection of its borders. ${ }^{14}$ In this study, the minimum and maximum size of patent ductus arteriosus were estimated by 2D and colour Doppler echocardiography and were compared with the data obtained by angiography.

\section{Materials and Methods}

Fifty cases were enrolled at pediatric cardiology department of BSMMU from January 2014 to January, 2016 in this study. The aortic and pulmonary end diameters of the patent ductus arteriosus and its length were measured with 2D and CDE and angiographically.

Patient with uncomplicated PDA were included in the study. Patients weighing less than $<5 \mathrm{~kg}$, age less than $<3$ months, active endocarditis or other infections producing bacteraemia, presence of thrombus at the intended site of implant or documented evidence of thrombus at the vessels through, which access is gained, patients whose vasculature through, which access to the defect is gained is inadequate to accommodate the appropriate sheath size, patients with pulmonary hypertension with PVR >8 Wood units or $\mathrm{Rp} / \mathrm{Rs}>0.4$, echocardiographic and angiographic estimations of the PDA sizes were made independently by the respective paediatric cardiology echocardiographer and interventionist who were blinded to each other's findings were excluded from the study.

Study protocol: One paediatric cardiologist performed colour doppler echocardiography examinations on all the patients to minimise the errors. Before catheterisation, each patient underwent a complete echocardiographic study with a General Electric-Vivid 7 echocardiographic machine (General Electic-Vivid 7 Vingmed, Horten, Norway), using a 4 megahertz probe, in parasternal short-axis and suprasternal views. The sector angle was between 45 and 60 degrees to permit high-quality frames. The patent ductus arteriosus flow was imaged using colour doppler echocardiography and the measurements were made at the narrowest and widest parts of the turbulent colour stream flow; gain was set at 50, the baseline was set at zero, the velocity scale was 4000 hertz, the frequency was 4 megahertz, and low velocity rejection was 3 centimetres per second in all the measurements performed three times in each view and the mean value was used for comparison. Angiographic estimations of the minimum and maximum diameters of patent ductus arteriosus were obtained with an ascending aortogram, using 1 millilitre per kilogram nonionic contrast through an appropriate pigtail catheter in the straight lateral camera position. The angiographic measurements were made off-line, calibrated to the catheter size. Catheterisation was performed under general anaesthesia and postdevice closure aortography was performed for the assessment of the residual shunt. The children were discharged after getting 7 days of antibiotics after the procedure as per institutional protocol.

Statistical analysis: Data are presented as range of values, median or mean values, and standard deviation for the purpose of comparison with other studies. Pearson correlation was used to calculate the degree of interrelation between echocardiographic and angiographic measurements. The difference between the methods was also calculated and checked for significance by using a two-tailed paired Student's $t$-test. A $p$-value of less than 0.05 was considered as statistically significant. SPSS version 20 statistical software was used for all the statistical analyses. 


\section{Results}

Fifty children were included in the study. The patient ages ranged from of 10 months and 28 years with a mean age of $5.75 \pm 5.33$ years. The mean weight was $16.37 \pm 10.58 \mathrm{Kg}$ with a range of $5.5 \mathrm{Kg}$ to $54 \mathrm{~kg}$. And sex distribution was 16 males and 34 females. As regards the type of PDA, $94 \%$ belonged to type A and $4 \%$ was type B based on Krichenko's classification. Visualization of the patent ductus arteriosus was achieved from short-axis and suprasternal-axis views in all children with colour doppler echocardiography. The mean diameter of pulmonary end of patent ductus arteriosus was $3.45 \pm 0.96$ millimetre with a range from 1.45 to 6.20 millimetres in color doppler echocardiography. The mean diameter of aortic end of PDA $4.64 \pm 1.30$ with a range of 2.50 to 9.50 in 2D and Color doppler echocardiography respectively. The mean angiographic measurement of aortic end of PDA was $5.35 \pm 1.42$ with a range of 2.60 to 10 . Both 2D echo and color doppler measurements correlated significantly with angiographic measurement at both pulmonary and aortic ends. The Pearson correlation coefficient for 2D echo and color doppler are 0.967 and 0.973 respectively at pulmonary end indicating that color Doppler echo correlates marginally better than 2D echo with angiographic measurements at the pulmonary end. Similarly at the aortic end (ampulla), the Pearson correlation coefficient for 2D echo and color Doppler are 0.955 and 0.966 respectively indicating that both correlates with angiography but color Doppler echo (CDE) is better correlates. Commonest size of device used in this study were $8 / 10$ followed by $10 / 12,6 / 8,5 / 3,14 / 12,12 / 10,4 / 6$.

Table I: Distribution of age

\begin{tabular}{lll}
\hline Age (Years) & Frequency & Percent \\
\hline$\leq 5$ & 29 & 58.0 \\
$5-10$ & 13 & 26.0 \\
$>10$ & 8 & 16.0 \\
Total & $\mathbf{5 0}$ & $\mathbf{1 0 0 . 0}$ \\
Mean \pm & SD & $5.75 \pm 5.33(0.10-28.00)$ \\
(Range) & \multicolumn{2}{l}{} \\
\hline
\end{tabular}

Table II: The comparison between the 2D echocardiography and angiography regarding the pulmonary end

\begin{tabular}{|c|c|c|c|c|c|c|c|}
\hline \multirow{2}{*}{$\begin{array}{l}\text { Pulmonay } \\
\text { End (mm) }\end{array}$} & \multirow{2}{*}{ Mean \pm SD } & \multirow{2}{*}{ Range } & & \multicolumn{2}{|c|}{ Paired test } & \multicolumn{2}{|c|}{ Correlations } \\
\hline & & & & $\mathbf{t}$ & $p$ value & $\mathbf{r}$ & $p$ value \\
\hline ANGIO & $3.62 \pm 1.03$ & $1.60-6.36$ & & & & & \\
\hline $2 \mathrm{D}$ & $3.24 \pm 0.95$ & $1.35-6.00$ & $\begin{array}{l}\text { 2D vs } \\
\text { Angio }\end{array}$ & 10.113 & $<0.001$ & 0.967 & $<0.001$ \\
\hline $\mathrm{CDE}$ & $\begin{array}{c}3.45 \pm \\
0.96\end{array}$ & $\begin{array}{l}1.45- \\
6.20 \\
\end{array}$ & $\begin{array}{r}\text { CDE vs } \\
\text { Angio }\end{array}$ & 4.829 & $<0.001$ & 0.973 & $<0.001$ \\
\hline
\end{tabular}

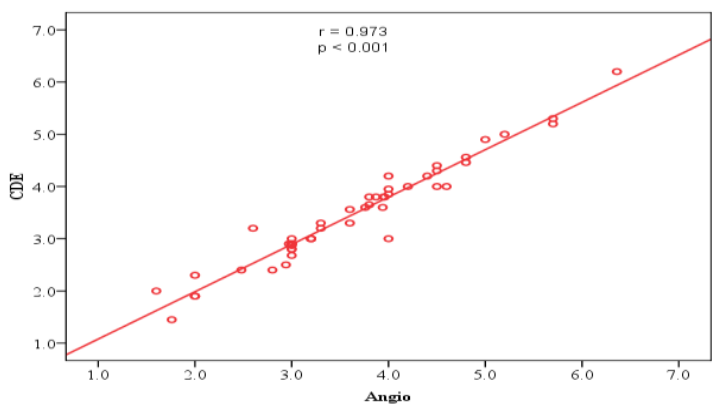

Figure 1: Correlation between CDE and angiography regarding the pulmonary end

Table III: The comparison between the 2D echocardiography and angiography regarding the aortic end

\begin{tabular}{|c|c|c|c|c|c|c|c|}
\hline \multirow{2}{*}{$\begin{array}{c}\text { Aortic } \\
\text { End } \\
\text { (Ampulla) } \\
(\mathbf{m m})\end{array}$} & \multirow{2}{*}{$\begin{array}{c}\text { Mean } \\
\pm \text { SD }\end{array}$} & \multirow{2}{*}{ Range } & & \multicolumn{2}{|c|}{ Paired test } & \multicolumn{2}{|c|}{ Correlations } \\
\hline & & & & $\mathbf{t}$ & $p$ value & $\mathbf{r}$ & $\begin{array}{c}p \\
\text { value }\end{array}$ \\
\hline ANGIO & $\begin{array}{c}5.35 \\
\pm \\
1.42\end{array}$ & $\begin{array}{l}2.60- \\
10.00\end{array}$ & & & & & \\
\hline $2 \mathrm{D}$ & $\begin{array}{c}4.64 \\
\pm \\
1.30\end{array}$ & $\begin{array}{l}2.50- \\
8.90\end{array}$ & $\begin{array}{l}2 \mathrm{D} \text { vs } \\
\text { Angio }\end{array}$ & 11.891 & $<0.001$ & 0.955 & $<0.001$ \\
\hline $\mathrm{CDE}$ & $\begin{array}{c}4.88 \\
\pm \\
1.36\end{array}$ & $\begin{array}{c}2.50- \\
9.50\end{array}$ & $\begin{array}{c}\text { CDE } \\
\text { vs } \\
\text { Angio }\end{array}$ & 9.076 & $<0.001$ & 0.966 & $<0.001$ \\
\hline
\end{tabular}

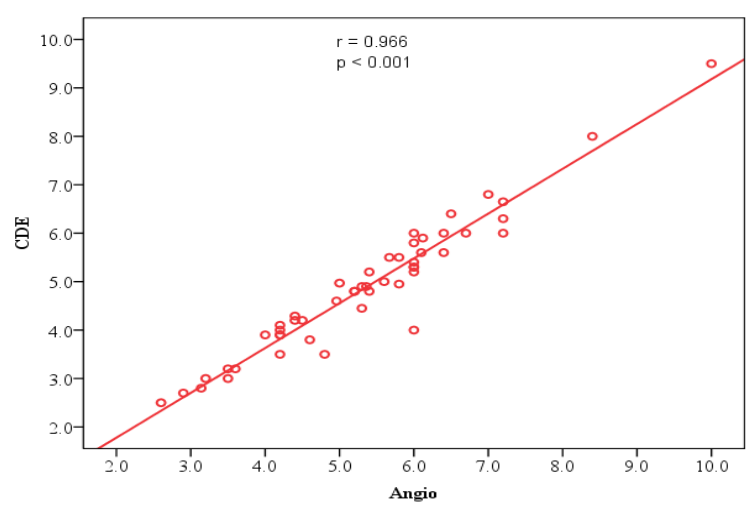

Figure 2: Correlation between CDE and angiography regarding the aortic end

\section{Discussion}

This study reveals that size estimation of patent ductus arteriosus by colour doppler echocardiography overestimates the exact diameter and has a statistical correlation with angiographic data. Patients who had a patent ductus arteriosus with a left to right shunt as cases; this selection may have increased the results of visualisation in echocardiography and the accuracy of the results. ${ }^{13}$ Exclusion of congenital defects 
that influence patent ductus arteriosus morphology, for example, pulmonary stenosis, also interferes with accurate measurement in echocardiography, because altered morphology makes the visualization of the patent ductus arteriosus difficult. All cases were also selected based on the criteria of "weight" and "clinical signs". Patients with a small patent ductus arteriosus and those with a large patent ductus arteriosus were included in this study. Echocardiographic visualisation data of a patent ductus arteriosus and its measuring accuracy are very diverse. ${ }^{10,13,15}$ Transthoracic colour doppler echocardiography can almost always visualise a patent ductus arteriosus in humans. No significant correlation with angiographic measurement has been proven in any study to date. ${ }^{10,15}$ Reports has been showen that two-dimensional echocardiography can obtain a comprehensive assessment of a patent ductus arteriosus and some measurements can be used to assess the suitability for device closure before angiography. ${ }^{16}$ There are some possible explanations for the difference between the results of the studies. First, we used fixed preset colour doppler echocardiography values in all measurements, but previous studies changed the colour baseline to lower values. ${ }^{10,15}$ Second, because of the limited lateral resolution of echocardiography and the relatively small diameter of the ductus in some of the studies, it is difficult to correctly visualise and measure such a small-sized diameter. Lastly, a low range of measured values automatically results in a poor correlation between the two measurement methods. ${ }^{10,14,16}$ The distance between the two examinations in terms of time may also be a reason for the differing results. Accordingly, an interval of up to 4 months was chosen between the two examinations in another study. ${ }^{10}$ During this period of time, the minimum patent ductus arteriosus diameter can increase as a result of dilatation or can decrease as a result of partial constriction. There was also a difference in the ultrasonographic technology used. ${ }^{17}$ In Colour Doppler echocardiography the colour field extends beyond the anatomical structures, overestimates the true diameter of a patent ductus arteriosus "bleeding of the colour flow". 10 This effect is particularly strong when colour amplification is high and the Nyquist limit is low. The true minimal diameter is particularly overestimated at low brightness settings because of the difficulty of endocardiac delimitation. ${ }^{19}$ But modern ultrasonic devices with better lateral resolution can minimise this problem which is postulated by the investigators. ${ }^{18} \mathrm{~A}$ further explanation may be that the minimal patent ductus arteriosus diameter cannot be visualised with exactly the same correct lateral projection in echocardiography as in angiography. ${ }^{10,14,15}$ A similar overestimation with colour Doppler echocardiography has also been reported in humans - greater than1 millimetre in $33 \%$ and greater than 2 millimetres in $19 \%$ of the patients $^{10}$ In one human study succeesfully visualised the patent ductus arteriosus by means of two-dimensional echocardiography in $30 \%$ of the patients but was not able to prove a significant correlation with angiography. ${ }^{10}$ Two other studies measured the patent ductus arteriosus in $100 \%$ of the patients with two-dimensional echocardiography; this value correlated significantly $(r=550.9711$ and 50.9410) with angiographic data, and there was a slight overestimation when the patent ductus arteriosus was somewhat narrower. The data of this study for the visualisation of the patent ductus arteriosus in two-dimensional echocardiography and colour Doppler echocardiography with left parasternal views $(100 \%)$ were comparable to those of the last two studies mentioned above. ${ }^{15,16}$ The use of highquality ultrasonic devices and transducers combined with examiner's experience can increase the accuracy of echocardiographic patent ductus arteriosus size estimation. According to other studies, there is a significant correlation between the size of patent ductus arteriosus in twodimensional echocardiography and angiography, but the small diameter of the patent ductus arteriosus makes defining of the borders difficult. $^{10,15,16}$ This study suggests that colour doppler echocardiography can always detect the patent ductus arteriosus easily, but it overestimates the diameters of the patent ductus arteriosus and there is a relatively fine correlation between the diameters of the patent ductus arteriosus in colour doppler echocardiography and angiography.

This study was conducted with a relatively small number of patients and used a retrospective crosssectional study design. The age distribution was 
wide for quantitative analysis of cardiac and pulmonaryhemodynamics. Sources of error in the measurement of pisa included the presence of an eccentric jet, non-hemispheric geometry of proximal flow convergence, imprecise identification of regurgitant orifce, and dynamic changes of the pisa radius throughout systole, for the letter reason, just 1 frame per systole was used and the systolic frame with the largest flow convergence region and as near as possible to the pda peak velocity was chosen. It may be a limitation of the present study that the catheterization and echocardiographic studies were not performed simultaneously; however, because the time interval between the two studies was short and there were no significant hemodynamic changes during this period, this limitation my be negligible. In spite of these limitations, there were significant correlations between vcw (vena contracta width), pda-esoa (effective shunt orifice area), and the cardiac catheterization findings. Recent technological advances in $3 \mathrm{~d}$ echocardiography (3de) have provided new tools for $\mathrm{mr}$ quantification using $\mathrm{vcw}$ and eroa, and $3 \mathrm{~d}$ imaging is particularly helpful when there are multiple or complicated jets. ${ }^{19}$ The pisa method using 3de can evaluate not only valvular disease but also congenital heart disease. ${ }^{20}$ The two current approaches for managing patients with pda are observation and elective ductal closure. Management decisions depend on the size of the left-to-right shunt, and the age and size of the patient. Further studies are needed to evaluate the validity of pda quantifaction by the 2 de pisa method using new tools such as 3 de and cardiac magnetic resonance. In conclusion, the $\mathrm{vcw}$ and pda-esoa calculated by pisa are both affected by pda morphology and have color flow jet characteristics. Measurement of vcw and pda-esoa can noninvasively evaluate the hemodynamic status of pda.

PDA size can also be measured by other modalities test by CT Aortogram (peripheral CT angiogram).

\section{Conclusion}

Analysing all data, in this study male female ratio is $1: 2$. The commonest age group involved in the present study is 5 years. Device closure done at this age can go a long way in preventing many of the long-term complications of persistent patent ductus arteriosus. The commonest type of the ductus in the present study is the type a based on krichenko's classification. It may be concluded that it is almost always possible to measure the dimensions of the patent ductus arteriosus with colour Doppler echocardiography. However, echocardiographic measurement overestimates the angiographic measurement of the pulmonary side of the patent ductus arteriosus and underestimates its aortic side, which should be considered for the measurement of the size of the patent ductus arteriosus. For non surgical interventional technique of PDA closure, size of PDA accurately should be done successful closing of PDA help in survival of child with PDA.

\section{References}

1. Neal WA, Bessinger FB Jr., Hunt CE, Lucas R: Patent ductus arteriosus complicatingrespiratory distress syndrome. J Pediatr 86: 127, 1975.

2. Zachman RD, Steinmetz GP, Botham RJ, Graven SN, Ledbetter MK: Incidence and treatment of the patent ductus arteriosus in the ill premature neonate. Am Heart J 87: 697,1974.

3. Siassi B, Emmanouilides GC, Cleveland RJ, Hirose F: Patent ductus arteriosus complicating prolonged assisted ventilation in respiratory distress syndrome. J Pediatr 74: 11,1969.

4. Kitterman JA, Edmunds LH, Gregory GA, Heymann MA,Tooley WH, Rudolph AM: Patent ductus arteriosus in premature infants: incidence, relation to pulmonary disease and management. N Engl J Med. 287:473.

5. Rao PS. Coil occlusion of patent ductus arteriosus. J Invasive Cardiol. 2001; 13:36-38.

6. Atiq M, Aslam N, Kazmi KA. Transcatheter closure of small to large patent ductus arteriosus with different devices: queries and challenges. J Invasive cardiol. 2007; 19:295-298.

7. Lin CC, Hsieh KS, Huang TC. Closure of large patent ductus arteriosus in infants. Am J Cardiol. 2009; 103: 857-861.

8. Santoro G, Gaio G, Carrozza M, Palladino MT, Russo MG, Calabro R. Large patent ductus arteriosus closure with multiple controlled-release coils. Int J of Cardiol. 2007; 116:425-426.

9. Wong JA, Shim D, Khoury PR, Meyer R. Validation of color Doppler measurements of minimum patent 
ductus significance for coil embolization. Am Heart J. 1988; 136:714-717.

10. Nakajima $T$, Ogawa $M$, Sano $T$, Matsushita $T$, Kayatani F, Yabbuchi H. Doppler echocardiographic estimation of pressured gradients. Pediatr Cardiol Cardiac Surg. 1990; 5:373-383.

11. Turner DR, Forbes TJ, Epstein ML, Wincent JA. Early reopening and recanalization after successful coil occlusion of the patent ductus arteriosus. Am Heart J. 2002; 143:889-893.

12. Torres A, Srivastava S, Parness I, Bridges ND. Echocardiography predictors of failure in patients undergoing coil occlusion of patent ductus arteriosus. J Am Soc Echocardiogr. 2003; 16:1063-1067.

13. Azhar AS, Abd El-Azim AA, Habib HS. Transcatheter closure of patent ductus arteriosus: Evaluating the effect curve on the outcome. Ann Pediatr Cardiol 2009; 2:36-40.

14. Bland JM, Altman DG. Statistical methods for assessing agreement between two methods of clinical measurement. Lancet. 1986; 1:307-310.

15. Ramaciotti C, Lemler MS, Moake L, Zellers TM. Comprehensive assessment of patient ductus arteriosus by echocardiography before transcatheter closure. J Am Soc Echocardiogr. 2002; 15:1154-59.

16. Hiraishi S, Horiguchi Y, Fujino N. Two-dimentional and Doppler echocardiographic assessment of variably shaped ductus arteriosus by the parasternal approach. Pediatr Cardiol. 1991; 12: 6-12.

17. Ewert P. Challenges encountered during closure of patent ductus arteriosus. Pediatr Cardiol. 2005; 26: 224-229.

18. Sahn DJ, Allen HD. Real-time cross-sectional echocardiographic imaging and measurement of the patent ductus arteriosus in infants and children. Circulation. 1978; 58:343-354.

19. Thavendiranathan $\mathrm{P}$, Phelan D, Collier P, Thomas JD, Flamm SD, Marwick TH. Quantitative assessment of mitral regurgitation: How best to do it. JACC Cardiovasc Imaging 2012; 5:1161-1175.

20. Ishii M, Hashino K, Eto G, Tsutsumi T, Himeno W, Sugahara Y, et al. Quantitative assessment of severity of ventricular septal defect by three-dimensional reconstruction of color Doppler-imaged vena contracta and flow convergence region. Circulation. 2001; 103:664-66. 